\title{
Vegetable variety: an effective strategy to increase vegetable choice in children
}

\author{
Tamara Bucher ${ }^{1, *}$, Michael Siegrist ${ }^{1}$ and Klazine van der Horst ${ }^{1,2}$ \\ ${ }^{1}$ ETH Zürich, Institute for Environmental Decisions (IED), CHN J 75.3, Universitätstrasse 16, 8092 Zurich, \\ Switzerland: ${ }^{2}$ Nestec Ltd, Nestlé Research Center, Food Consumer Interaction Department, Lausanne, \\ Switzerland
}

Submitted 24 January 2013: Final revision received 13 June 2013: Accepted 25 July 2013: First published online 10 0ctober 2013

\begin{abstract}
Objective: Most children do not meet the recommended intake of vegetables. Variety was identified as a potential factor to increase children's intake of these foods, as it was shown that variety was effective in improving meal composition in adults. Because younger children are suggested to be more responsive to internal satiation signals than to external food-related cues compared with adults, it is not clear whether variety is effective to improve meal composition in 7- to 10-year-old children.

Design: Experiment.

Setting: Children were assigned one of three different fake food buffets containing pasta, chicken, and either one vegetable (carrots or beans) or two vegetables (carrots and beans). The children were asked to serve themselves a meal that they would like to eat for lunch from the given selection.

Subjects: One hundred children (fifty-two boys; mean age $8 \cdot 8$ (SD $1 \cdot 1$ ) years).

Results: Children given the two-vegetable choice served themselves significantly more energy from vegetables (mean 64 (SD 51) kJ, 10.9 (SD 9.4) \%) compared with children who were offered only either carrots (mean 37 (SD 25) kJ, 5.9 (SD 6.5) \%) or beans (mean 38 (sD 34) kJ, 5.6 (sD 6.3) \%). The total energy of the meal was not increased, indicating that children chose a more balanced lunch when offered more vegetables.

Conclusions: School-aged children are responsive to food-related cues and variety is effective in increasing their vegetable choice. Serving an assortment of vegetables in school cafeterias might be a simple and effective strategy to improve children's nutrition.
\end{abstract}

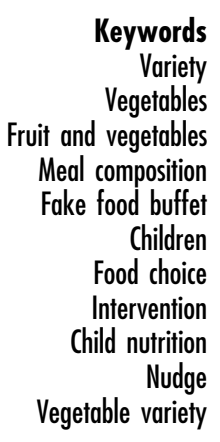

As the evidence for the health benefits of a diet rich in fruit and vegetables is substantial ${ }^{(1)}$, the WHO recommends a daily intake of at least $400 \mathrm{~g}$ of these foods which, unfortunately, most children do not meet ${ }^{(2)}$. As low intakes of fruit and vegetables track into adolescence and adulthood ${ }^{(3,4)}$, many campaigns are trying to increase the intake of these healthy foods in children. Fruit and vegetable variety was suggested as a potential factor that may increase choice of these foods in schoolchildren ${ }^{(5)}$. Vegetable variety was shown to improve meal composition in adults ${ }^{(6)}$. If two vegetables were offered instead of one, people served themselves a higher proportion of energy from vegetables while the overall energy of the meal was not altered ${ }^{(6)}$. A similar result was found by Meengs et $a l^{(7)}$.

However, even though vegetable variety was shown to be effective in improving the composition of adults' meals, it is not clear whether vegetable variety also improves the composition of children's meals. A randomized controlled trial that examined the effect of choice offering on consumption of vegetables in 4- to 6-year-olds did not show an increased intake ${ }^{(8)}$. When younger children select a meal, food-related cues such as variety might be of minor importance, while the responsiveness to liking or signals such as hunger and satiety might be more important ${ }^{(9)}$. Recently, an observational study found that the fraction of children who ate at least one serving of fruit and vegetables during lunch was higher in schools that offered more fruit and vegetables ${ }^{(10)}$.

The fake food buffet, a new method that uses replica food items for experimental investigation of food choice, has recently been proved a reliable and valid method to investigate the effect of external influences ${ }^{(11)}$. It was shown that the amount of food served from fake foods is highly correlated with the amount of food served from a buffet containing the corresponding real food items ${ }^{(11)}$. Using fake foods instead of real foods for experimental studies reduces food waste, preparation effort and costs, 
Table 1 Descriptive characteristics of the study population and correlation analysis (Pearson's correlation coefficient $r$ ) of control variables with the outcome variables total energy from vegetables, total energy from meal and percentage of energy from vegetables: children aged 7 to 10 years and their parents

\begin{tabular}{|c|c|c|c|c|c|}
\hline & \multicolumn{2}{|c|}{$\begin{array}{c}\text { Total } \\
\text { (n 100, fifty-two boys) }\end{array}$} & \multirow{2}{*}{$\begin{array}{c}\begin{array}{c}\text { Total energy from } \\
\text { vegetables }(\mathrm{kJ})\end{array} \\
r\end{array}$} & \multirow{2}{*}{$\begin{array}{c}\begin{array}{c}\text { Total energy from } \\
\text { meal }(\mathrm{kJ})\end{array} \\
r\end{array}$} & \multirow{2}{*}{$\begin{array}{l}\begin{array}{l}\text { Percentage of energy } \\
\text { from vegetables }(\mathrm{kJ})\end{array} \\
r\end{array}$} \\
\hline & Mean & SD & & & \\
\hline Age (years) & $8 \cdot 8$ & $1 \cdot 1$ & -0.025 & $0 \cdot 105$ & -0.072 \\
\hline BMI percentilet & $52 \cdot 2$ & $24 \cdot 6$ & $0.211^{*}$ & 0.036 & $0 \cdot 161$ \\
\hline Level of hunger $\ddagger$ & $1 \cdot 6$ & 0.6 & 0.055 & 0.052 & -0.066 \\
\hline Picky eating $\$$ & $19 \cdot 6$ & $7 \cdot 3$ & $-0.350^{\star *}$ & 0.006 & $-0.270^{\star}$ \\
\hline \multicolumn{6}{|l|}{ Preferencesll } \\
\hline Cooked carrots & $2 \cdot 2$ & $1 \cdot 1$ & $0 \cdot 319^{\star \star}$ & $-0.296^{\star \star}$ & $0 \cdot 324^{* *}$ \\
\hline Cooked beans & $2 \cdot 6$ & $1 \cdot 3$ & $0.608^{\star \star}$ & -0.065 & $0.457^{\star \star}$ \\
\hline Fried chicken & $2 \cdot 0$ & $1 \cdot 1$ & $0 \cdot 149$ & $0 \cdot 402^{\star \star}$ & $0 \cdot 149$ \\
\hline Pasta & $1 \cdot 4$ & $0 \cdot 7$ & 0.032 & $0 \cdot 122$ & 0.032 \\
\hline Parental education & $5 \cdot 7$ & $1 \cdot 8$ & 0.015 & -0.026 & 0.015 \\
\hline
\end{tabular}

*Significant at $P<0.01,{ }^{* *}$ significant at $P<0.001$. No significant differences were found between the experimental groups.

tBMI percentiles were calculated from children's weight and height measures using the Centers for Disease Control and Prevention growth charts. fHunger levels were measured on a three-point scale $(1=$ 'not hungry' to $3=$ 'hungry').

\$Picky eating was assessed with a six-item scale (Cronbach's $\alpha=0.88$ ) within the parents' questionnaire. The items were derived from Wardle et al. ${ }^{(12)}$

IIFood preferences were measured on a five-point scale ( $1=$ 'I like it very much' to $5=$ 'I don't like it at all').

'Parental education was measured in categories ranging from $1=$ 'no education' to 8 = 'university degree'. The data were analysed using non-parametric statistics; Spearman's correlation coefficients are reported.

as the items do not need to be cooked and are reused. Most importantly, the fake food buffet allows for the study of individual subjects under controlled laboratory conditions. Therefore, this method is very suitable for the investigation of environmental influences on food choice.

In the present study, we used a fake food buffet to assess whether vegetable variety improves 7 - to 10 -year-old children's meal composition. We used the same experimental setting that was applied in our previous study, where we showed that vegetable variety is effective to improve adults' meal composition $^{(6)}$.

\section{Methods}

\section{The fake food buffet}

We used a fake food buffet for the experiment. For the present study, a buffet was prepared with four replicas of foods commonly eaten for a hot meal in Switzerland: carrots, green garden beans, pasta and fried skinless chicken breast. The replica foods were obtained from Döring $\mathrm{GmbH}$, Munich (Germany). The replica food items were placed on a small table in metal serving dishes. The energy content of the fake foods was estimated by comparison with corresponding real food items. Further methodological details are presented elsewhere ${ }^{(6,11)}$.

\section{Participants}

Children aged 7 to 10 years and their parents were invited by mail to participate in a study about children's food preferences. One hundred children participated in the study (fifty-two boys). Children following a medically prescribed diet were excluded from participation. Written informed consent was obtained from all parents. Descriptive characteristics of the study population can be found in Table 1 .

\section{Experimental procedure}

Hunger and preference for the foods were assessed before the experiment. Each child was randomly assigned to one of three different replica food selections. The buffet under condition 'carrots' ( $n$ 32) consisted of cooked carrots, pasta and chicken; under condition 'beans' ( $n$ 34), children could serve themselves green beans, pasta and chicken; and under condition 'carrots \& beans' ( $n$ 34), children were offered both vegetables in addition to pasta and chicken. In the experiment each child was asked to serve him- or herself a meal, from the presented selection, such as they would like to eat for lunch from the presented selection on a normal school day. The experiment took place in the absence of the parent. The child's height and weight were measured by the experimenter.

\section{Measures}

The theoretical energy of the fake foods was determined by weighing the replica foods and multiplying the weight by a conversion factor to correct for weight differences between fake and real foods ${ }^{(6)}$. The outcome variable percentage of energy from vegetables was determined by computing the relative energy from vegetables compared with the total energy.

Measured weight and height were used to calculate the children's BMI (weight in kilograms divided by the square of height in metres $\left(\mathrm{kg} / \mathrm{m}^{2}\right)$ ). Hunger was measured with the question 'How hungry do you feel right now?' on a three-point scale ( $1=$ 'not hungry', $2=$ 'medium', $3=$ 'hungry'). Preferences were assessed with the question 'How much do you like this food?' on a five-point smiley scale ( $1=$ 'I like it very much' to $5=$ 'I don't like it at all'). Picky eating was assessed with a six-item scale (Cronbach's $\alpha=0.88)$ which was included in the parent's questionnaire. The items were derived from Wardle et al. ${ }^{(12)}$. 


\section{Statistical analysis}

Data were analysed using the statistical software package IBM SPSS Statistics Version 19. Univariate ANOVA was conducted to determine whether the buffet conditions were associated with the three outcome variables. Effect sizes $\left(\eta^{2}\right)$ are reported. In the case of a significant omnibus $F$ test, planned group comparisons were made using the Bonferroni correction ( $P$ values of the least significant difference test are multiplied by the number of comparisons). Means, standard deviations and Pearson correlation coefficients $(r)$ are reported. All tests are based on a 0.05 significance level.

\section{Results}

One-way ANOVA did not detect any significant differences between the experimental groups in terms of age (mean 8.8 (SD 1.1) years), BMI percentile (mean 52.2 (SD 24.6)), preference for the offered food items (carrots: mean $2 \cdot 2$ (SD 1.1); beans: mean $2 \cdot 6$ (SD 1.3); pasta: mean $1 \cdot 4(\mathrm{SD} 0 \cdot 7)$; chicken: mean $2 \cdot 0(\mathrm{SD} 1 \cdot 1)$ ), hunger (mean $1 \cdot 6(\mathrm{SD} 0 \cdot 6)$ ) or picky eating (mean 19.6 (SD 7·3)).

To test whether vegetable variety affects the total energy from vegetables $(\mathrm{kJ})$, the means of the energy derived from vegetables were compared between experimental groups (Table 2 ). ANOVA revealed a significant main effect $\left(F_{(2,97)}=5 \cdot 10, P=0 \cdot 008, \eta^{2}=0 \cdot 10\right)$. The energy derived from vegetables increased significantly when two vegetables were offered instead of only one. Planned contrasts showed statistically significant differences between the condition 'carrots \& beans' (mean 64 (SD 51) kJ) and conditions 'carrots' (mean 37 (sD 25) kJ, $P=0 \cdot 018$ ) and 'beans' (mean 38 (sD 34) kJ, $P=0 \cdot 025$ ).

The same results were observed when the percentage of energy from vegetables was analysed, which indicates that children offered two vegetables served themselves a healthier meal.

The variety of vegetables presented did not influence the total energy of the meal $\left(F_{(2,97)}=0 \cdot 81, P=0 \cdot 448\right.$, $\eta^{2}=0 \cdot 016$; Table 2). Note that the test results of the effect of the experimental condition on the outcome variables total energy from vegetables and percentage of energy from vegetables are similar. This is because the energy from the total meal was equal throughout the conditions. A visualisation of the proportions of foods served on the plate is found in Fig. 1.

Moreover, the amount of vegetables served $\left(t_{(98)}=0.30, P=0.77\right)$ and the total energy of the meal $\left(t_{(98)}=1 \cdot 43, P=0 \cdot 16\right)$ did not differ between genders. The preference ratings for the individual food items were significantly related to the amount of the item that was served (chicken: $r=0.52, \quad P<0.001$; pasta: $r=0.31$, $P=0 \cdot 002$; carrots: $r=0.33, P=0 \cdot 001$; beans: $r=0.57$, $P<0 \cdot 001)$. Picky eating was inversely related to the amount of vegetables scooped $(r=-0 \cdot 35, P<0 \cdot 001)$.

Table 2 Differences in meal composition depending on the experimental condition (one-way ANOVA): children aged 7 to 10 years ( $n 100$, fifty-two boys)

\begin{tabular}{|c|c|c|c|c|c|c|c|c|c|c|c|}
\hline & \multicolumn{2}{|c|}{$\begin{array}{l}\text { Total } \\
(n 100)\end{array}$} & \multicolumn{2}{|c|}{$\begin{array}{l}\text { Carrots } \\
(n \text { 32) }\end{array}$} & \multicolumn{2}{|c|}{$\begin{array}{l}\text { Beans } \\
(n \text { 34) }\end{array}$} & \multicolumn{2}{|c|}{$\begin{array}{l}\text { Carrots \& beans } \\
\quad(n \text { 34) }\end{array}$} & \multirow[b]{2}{*}{$F_{(2,97)}$} & \multirow[b]{2}{*}{$P$} & \multirow[b]{2}{*}{$\eta^{2}$} \\
\hline & Mean & SD & Mean & SD & Mean & SD & Mean & SD & & & \\
\hline Total energy from vegetables $(\mathrm{kJ})$ & 46 & 40 & $37^{b}$ & 25 & $38^{\mathrm{b}}$ & 34 & $64^{\mathrm{a}}$ & 51 & $5 \cdot 10$ & 0.008 & 0.095 \\
\hline Total energy from meal $(\mathrm{kJ})$ & 759 & 297 & 725 & 282 & 811 & 256 & 739 & 297 & 0.81 & 0.448 & 0.016 \\
\hline Percentage of energy from vegetables $(\mathrm{kJ})$ & $7 \cdot 5$ & $7 \cdot 9$ & $5 \cdot 9^{\mathrm{b}}$ & $6 \cdot 5$ & $5 \cdot 6^{b}$ & $6 \cdot 3$ & $10 \cdot 9^{a}$ & $9 \cdot 5$ & $5 \cdot 14$ & 0.008 & 0.096 \\
\hline
\end{tabular}

${ }^{\mathrm{a}, \mathrm{b}}$ Mean values within a row with unlike superscript letters were significantly different $(P<0 \cdot 05)$. Bonferroni post hoc tests are reported $(\alpha=0 \cdot 05)$.

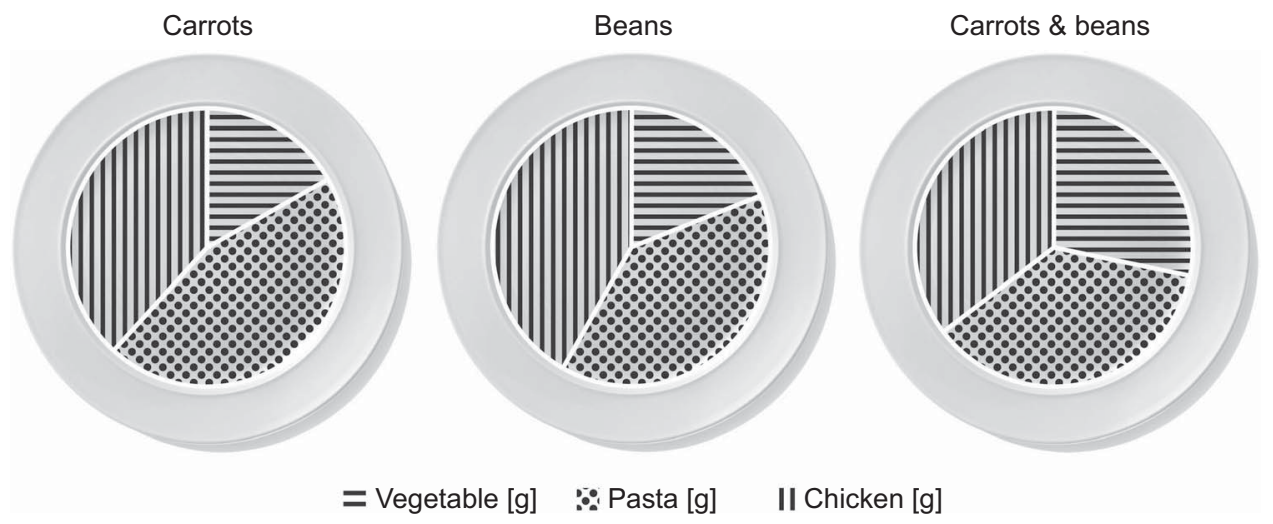

Fig. 1 Visualisation of the food proportions on the plate. Children who were offered two vegetables instead of one chose a more balanced meal, containing a higher proportion of vegetables (grams of food were calculated based on the energy per $100 \mathrm{~g}$ values derived from the SwissFIR nutrient database ${ }^{(17)}$ ) 
Correlations of control variables with outcome variables are found in Table 1.

In addition to ANOVA, ANCOVA was conducted to control for the effect of children's preferences for chicken, pasta, carrots and beans on the outcome variables; and the analysis led to the same conclusions. The effect of the experimental condition on the served energy from vegetables and on the percentage of energy from vegetables was even higher when the preference ratings were included as covariates. The energy from vegetables was significantly higher in the two-vegetable group $\left(F_{(2,90)}=11 \cdot 7, P=<0 \cdot 001, \eta^{2}=0 \cdot 207\right)$, as was the percentage of energy from vegetables $\left(F_{(2,90)}=13 \cdot 34, P=<0 \cdot 001\right.$, $\left.\eta^{2}=0 \cdot 231\right)$. The energy of the meal was not affected by the experimental condition $\left(F_{(2,90)}=1 \cdot 34, P=0 \cdot 124\right.$, $\eta^{2}=0.029$ ), even after controlling for the preferences. Note that picky eating was not included in the ANCOVA, as the measure is related to the preferences for the vegetables. BMI percentiles were not included, as there was no significant covariation with the outcomes after controlling for preferences.

\section{Discussion}

While most children like fruits, they are pickier when it comes to vegetables. Increasing children's vegetable intake is therefore more difficult. In the present study we showed that vegetable variety has the potential to increase the amount of vegetables selected and thereby improve children's meal composition.

The percentage of energy from vegetables almost doubled from $6 \%(37 \mathrm{~kJ}$ and $38 \mathrm{~kJ})$ to $11 \%(64 \mathrm{~kJ})$ when two vegetables were served instead of only one. At the same time, the energy of the total meal was not changed, suggesting that children chose a healthier meal containing a higher proportion of energy from vegetables. The result is consistent with our previous findings in adults. In contrast to previous findings with younger children $^{(8)}$, we found a positive effect of offering a choice of vegetables to children aged 7 to 10 years. It might be that younger children are less responsive to food-related cues compared with older children.

The effect of variety on food consumption is commonly explained by a reduction of the so-called sensory-specific satiety $^{(13,14)}$. The phenomenon of sensory-specific satiety refers to the declining satisfaction generated by the consumption of a certain type of food and the subsequent renewal of appetite upon exposure to another stillpalatable food ${ }^{(14)}$. However, as the fake foods were not consumed, this explanation can be excluded. Rather, these data support previous findings from Kahn and Wansink, who showed that the mere perception of variety leads to increased consumption ${ }^{(15)}$. They showed that children took more jellybeans when they were organised according to colours than when they were scrambled together ${ }^{(15)}$. The authors suggested that the assortment structure could serve as a consumption rule that suggests a quantity that is acceptable to eat. For organised assortments, the number of categories might serve as a benchmark of how much should be consumed. Therefore, if a variety of vegetables are served in several serving bowls, children might assume that it is appropriate to serve at least a little bit from every bowl. This consumption rule could explain why children, as well as adults, served themselves more vegetables if they were offered two instead of only one item. Hence, this effect is likely to be lost if vegetables are scrambled together in a dish such as in ratatouille.

Studies on moderators of the variety effect in adults suggest that the sensory-specific satiety effect is very stable ${ }^{(16)}$. Children who participated in the present study were mostly of normal weight. Remick et al. found that, in general, internal moderators like weight or dietary restraint do not influence the effect of variety ${ }^{(16)}$. Therefore, we would not expect a different experimental outcome in a population of obese or overweight children. However, this would need to be tested by future research.

The foods chosen for our study were relatively low in energy. If non-vegetable items which would have been higher in energy density had been chosen, the energy of a meal could have been reduced by increasing the variety of vegetables. The findings are limited to food choice to a certain extent, as the replica foods were not consumed. Nevertheless, the result that choice can be improved is relevant, because once healthy foods are on the plate, the likelihood that they will also be consumed is higher. The children were asked to choose only foods that they would like to eat and the amounts of food chosen were related to their preferences. Furthermore, children who were classified as picky eaters based on their parents' assessment chose fewer vegetables. These findings are a measure of face validity and indicate that, overall, the children behaved naturally during the experiment.

\section{Conclusion}

Vegetable variety can increase the proportion of vegetables selected by both adults and children. Serving a bigger variety of vegetables at lunch in school cafeterias or afterschool nurseries seems to be a simple and effective strategy to improve children's food choices. Further research should investigate this within a natural eating environment.

\section{Acknowledgements}

Sources of funding: This research was supported by the Swiss Foundation for Nutrition Research (SFEFS). The SFEFS had no role in the design, analysis or writing of this article. Conflicts of interest: There are no conflicts of interest for this study. Ethics: The study was approved by the ethics committee of the ETH Zurich (EK 2012-N-37). 
Authors' contributions: T.B., M.S. and K.v.d.H. contributed to the design of the analysis. T.B. directed the study, conducted the analysis and wrote the manuscript by incorporating critical inputs from all authors. All authors approved the final manuscript. Acknowledgements: The authors are grateful to the families who participated in this research and to all who assisted in data acquisition.

\section{References}

1. Van Duyn MS \& Pivonka E (2000) Overview of the health benefits of fruit and vegetable consumption for the dietetics professional: selected literature. J Am Diet Assoc 100, 1511-1521.

2. Vereecken CA, De Henauw S \& Maes L (2005) Adolescents' food habits: results of the Health Behaviour in School-aged Children survey. Br J Nutr 94, 423-431.

3. Kelder SH, Perry CL, Klepp KI et al. (1994) Longitudinal tracking of adolescent smoking, physical-activity, and food choice behaviors. Am J Public Health 84, 1121-1126.

4. te Velde SJ, Twisk JWR \& Brug J (2007) Tracking of fruit and vegetable consumption from adolescence into adulthood and its longitudinal association with overweight. Br J Nutr 98, 871-871.

5. Krolner R, Rasmussen M, Brug J et al. (2011) Determinants of fruit and vegetable consumption among children and adolescents: a review of the literature. Part II: qualitative studies. J Behav Nutr Phys Act 8, 112.

6. Bucher T, van der Horst K \& Siegrist M (2011) Improvement of meal composition by vegetable variety. Public Health Nutr 14, 1357-1363.
7. Meengs JS, Roe LS \& Rolls BJ (2012) Vegetable variety: an effective strategy to increase vegetable intake in adults. J Acad Nutr Diet 112, 1211-1215.

8. Zeinstra GG, Renes RJ, Koelen MA et al. (2010) Offering choice and its effect on Dutch children's liking and consumption of vegetables: a randomized controlled trial. Am J Clin Nutr 91, 349-356.

9. Ashcroft J, Semmler C, Carnell CM et al. (2008) Continuity and stability of eating behaviour traits in children. Eur J Clin Nutr 62, 985-990.

10. Just DR, Lund J \& Price J (2012) The role of variety in increasing the consumption of fruits and vegetables among children. Agric Resour Econ Rev 41, 72-81.

11. Bucher T, van der Horst K \& Siegrist M (2012) The fake food buffet - a new method in nutrition behaviour research. Br J Nutr 107, 1553-1560.

12. Wardle J, Guthrie CA, Sanderson S et al. (2001) Development of the Children's Eating Behaviour Questionnaire. J Child Psychol Psychiatry 42, 963-970.

13. Rolls BJ, Rowe EA, Rolls ET et al. (1981) Variety in a meal enhances food intake in man. Physiol Behav 26, 215-221.

14. Rolls BJ, Rolls ET, Rowe EA et al. (1981) Sensory specific satiety in man. Physiol Behav 27, 137-142.

15. Kahn BE \& Wansink B (2004) The influence of assortment structure on perceived variety and consumption quantities. J Consum Res 30, 519-533.

16. Remick AK, Polivy J \& Pliner P (2009) Internal and external moderators of the effect of variety on food intake. Psychol Bull 135, 434-451.

17. ETH Zürich (2010) SwissFIR Database 2010. http:// nwdb.ethz.ch:8080/nwdb/request?xml=MessageData\&xml= MetaData\&xsl=SearchField\&lan=de (accessed September 2013). 